\title{
PENGARUH MOTIVASI INTRINSIK, KEPEMIMPINAN DAN DISIPLIN KERJA TERHADAP KINERJA PEGAWAI DINAS PEMBERDAYAAN MASYARAKAT DAN DESA KABUPATEN LABUHANBATU SELATAN
}

\author{
${ }^{1}$ Derwana, ${ }^{2}$ Khoiruddin Harahap, ${ }^{3}$ Ahmad Zubeir, ${ }^{4}$ Astuty Leonia, ${ }^{5}$ Mahmud Salim Harahap. \\ ${ }_{1,2,3,4,5}$ Universitas Islam Sumatera Utara \\ Iderwana.mm@gmail.com, 2khoiruddin.hrp@gmail.com,33hmad.zubeir@gmail.com, \\ ${ }^{4}$ astuty.leonia@gmail.com, ${ }^{5}$ mhd.salimhrp@gmail.com
}

\begin{abstract}
The problems in research what is influence of intrinsic motivation on performance. What is influence of leadership on performance. What is influence of job dicipline on performance. What is influence of intrinsic motivation, leadership and job dicipline on performance. The research of purposes is for know and analysis influence of intrinsic motivation on performance. For know and analysis influence of leadership on performance. For know and analysis influence of job dicipline on performance. For know and analysis influence of intrinsic motivation, leadership and job dicipline on performance. Samples in the research amount to 36 employees people. Data analyze technique in the research using descriptive analyze and regression analize. The results of this research explain of intrinsic motivation variable effect significant and positive on performance. leadership variable effect significant and positive on performance. Job dicipline variable effect significant and positive on performance. Intrinsic motivation, leadership and job dicipline variable effect significant and positive on performance.
\end{abstract}

Keywords : Intrinsic motivation, Leadership, Job dicipline, Performance

\begin{abstract}
ABSTRAK : Rumusan masalah dalam penelitian ini adalah apakah ada pengaruh motivasi intrinsik terhadap kinerja. Apakah ada pengaruh kepemimpinan terhadap kinerja. Apakah ada pengaruh disiplin kerja terhadap kinerja. Apakah ada pengaruh motivasi intrinsik, kepemimpinan dan disiplin kerja terhadap kinerja. Tujuan penelitian ini adalah untuk mengetahui dan menganalisis pengaruh motivasi intrinsik terhadap kinerja. Untuk mengetahui dan menganalisis pengaruh kepemimpinan terhadap kinerja. Untuk mengetahui dan menganalisis pengaruh disiplin kerja terhadap kinerja. Untuk mengetahui dan menganalisis pengaruh motivasi intrinsik, kepemimpinan dan disiplin kerja terhadap kinerja. Sampel dalam penelitian ini berjumlah 36 orang pegawai. Teknik analisis data dalam penelitian ini menggunakan analisis deskriptif dan analisis regresi linier berganda. Hasil penelitian ini menjelaskan bahwa variabel motivasi intrinsik berpengaruh positif dan signifikan terhadap kinerja. Variabel kepemimpinan berpengaruh positif dan signifikan terhadap kinerja. Variabel disiplin kerja berpengaruh positif dan signifikan terhadap kinerja. Variabel motivasi intrinsik, kepemimpinan dan disiplin kerja berpengaruh positif dan signifikan terhadap kinerja
\end{abstract}

Kata kunci : Motivasi intrinsik, Kepemimpinan, Disiplin kerja, Kinerja

\section{Pendahuluan}

Sebagai salah satu organisasi pemerintahan, Dinas Pemberdayaan Masyarakat Dan Desa Kabupaten Labuhanbatu Selatan merupakan perpanjangan tangan dari Pemerintah Kabupaten Labuhanbatu Selatan yang mempunyai tugas membantu Bupati melaksanakan urusan Pemerintahan Desa di bidang pemberdayaan dan partisipasi masyarakat, bidang usaha masyarakat dan sumber daya alam, dan bidang pemberdayaan teknologi tepat guna, bidang pemerintahan desa/kelurahan. Guna menjalankan tugas tersebut, maka Dinas Pemberdayaan Masyarakat Dan Desa Kabupaten Labuhanbatu Selatan harus didukung dengan adanya pendanaan, sarana prasarana dan sumber daya aparatur yang memadai. Dapat dikatakan bahwa 
Dinas Pemberdayaan Masyarakat Dan Desa Kabupaten Labuhanbatu Selatan masih perlu ditunjang dengan pendanaan, sarana prasarana dan SDM aparatur yang memadai tersebut sehingga pegawai dapat menghasilkan kinerja yang baik, karena pegawai merupakan aset utama organisasi dan mempunyai peran yang strategis didalam organisasi yaitu sebagai pemikir, perencana, dan pengendali aktivitas organisasi.

Pentingnya kinerja pegawai dalam melaksanakan program kerja Dinas Pemberdayaan Masyarakat Dan Desa Kabupaten Labuhanbatu Selatan semakin dirasakan. Menurut Rivai (2011:88) menjelaskan kinerja adalah perilaku nyata yang diperlihatkan oleh pegawai sebagai prestasi kerja yang dihasilkan sesuai dengan peranannya dalam organisasi. Menurut Siagian (2014:98), kinerja adalah hasil kerja secara kualitas dan kuantitas yang dicapai oleh seorang pegawai dalam melaksanakan tugasnya sesuai dengan tanggung jawab yang di berikan. Jadi kinerja dapat di pandang sebagai proses maupun hasil pekerjaan. Menurut Istijanto (2014:259), kinerja merupakan suatu proses tentang bagaimana pekerjaan berlangsung untuk mencapai hasil kerja. Oleh karena itu hasil kerja seorang pegawai, merupakan sebuah proses manajemen atau organisasi secara keseluruhan, dimana hasil kerja tersebut harus dapat di tunjukan buktinya secara konkrit dan dapat diukur (dibandingkan dengan standar yang telah ditentukan. Permasalahan kinerja pegawai di Dinas Pemberdayaan Masyarakat Dan Desa Kabupaten Labuhanbatu Selatan terlihat bahwa hasil pekerjaan pegawai belum optimal. Jadi guna meningkatkan kinerja pegawai agar dapat optimal maka diperlukan suatu motivasi yang berasal dari dalam diri pegawai.

Untuk meningkatkan kinerja pegawai Dinas Pemberdayaan Masyarakat Dan Desa Kabupaten Labuhanbatu Selatan agar lebih baik perlu ditunjang adanya motivasi dari dalam diri setiap pegawai atau motivasi intrinsik. Motivasi intrinsik adalah motif - motif yang menjadi aktif atau berfungsinya tidak perlu dirangsang dari luar karena dalam diri setiap individu sudah ada dorongan untuk melakukan sesuatu. Faktor intrinsik disebut juga motif atau pendorong. Jika dua faktor ada yaitu intrinsik dan ekstrinsik, maka pekerja dapat mencapai kepuasan kerja tetapi jika tidak ada bukan berarti kepuasan kerja tidak tercapai. Yang termasuk dalam faktor intrinsik adalah pencapaian, penguatan, tanggung jawab, peningkatan status tugas itu sendiri dan kemungkinan berkembang, Siagian (2014:133). Pernyataan diatas adalah merupakan beberapa anggapan yang nyata untuk kesuksesan suatu organisasi, begitu juga halnya di Dinas Pemberdayaan Masyarakat Dan Desa Kabupaten Labuhanbatu Selatan. Penelitian terdahulu yang menyatakan motivasi berpengaruh terhadap kinerja diantaranya penelitian dari Ruqo'iye (2012), Saeed at.al (2016), Ali at.al (2016), dan Nurchayani at.al (2016). Menurut Dessler (2013:117) motivasi adalah daya pendorong yang mengakibatkan seseorang mau dan rela mengerahkan kemampuan dalam bentuk keahlian atau keterampilan, tenaga dan waktunya untuk menyelenggarakan berbagai kegiatan yang menjadi tanggung jawabnya dalam rangka pencapaian tujuan organisasi. Seorang yang memiliki motivasi yang rendah mereka cenderung untuk memperlihatkan upaya yang tidak maksimal dalam melaksanakan pekerjaannya, sehingga semakin tinggi motivasi yang dimiliki oleh individu sebagai pegawai maka dapat meningkatkan kinerja pegawai itu sendiri. Dengan demikian, setiap organisasi perlu mengetahui apa yang menjadi motivasi para pegawainya, sebab faktor tersebut dapat menjadi salah satu faktor yang menentukan tinggi atau rendahnya motivasi seorang pegawai dalam melaksanakan pekerjaan. Fakta yang ditemukan pada pegawai Dinas Pemberdayaan Masyarakat Dan Desa Kabupaten Labuhanbatu Selatan 3 bulan terakhir menunjukkan bahwa disebabkan adanya dampak pandemi Covid-19 sehingga pekerjaan pegawai banyak dilakukan dari rumah, dan dari hasil pantauan peneliti terlihat motivasi sebagian pegawai untuk bekerja secara optimal masih kurang optimal, hal ini dapat dilihat dari proses penyelesaian suatu pekerjaan masih memerlukan waktu beberapa hari. Kondisi ini merefleksikan bahwa motivasi kerja pegawai Dinas Pemberdayaan Masyarakat Dan Desa Kabupaten Labuhanbatu Selatan masih belum baik.

Faktor lain yang memepengaruhi kinerja pegawai Dinas Pemberdayaan Masyarakat Dan Desa Kabupaten Labuhanbatu Selatan adalah kepemimpinan. Hal ini diperkuat dengan penelitian terdahulu dari Krisdiana (2014) dan Dwi Wahyu (2012) yang menyatakan kepemimpinan berpengaruh terhadap kinerja. Menurut pendapat Handoko (2015:76), untuk mencapai tujuan bersama, pegawai di dalam 
suatu organisasi perlu membina kebersamaan dengan mengikuti pengendalian dari pemimpinnya. Dengan pengendalian tersebut, perbedaan keinginan, kehendak, kemauan, perasaan, kebutuhan dan lain-lain dipertemukan untuk digerakkan kearah yang sama. Dengan demikian berarti di dalam setiap perbedaan individual dimanfaatkan untuk mencapai tujuan yang sama sebagai kegiatan kepemimpinan. Peran pemimpim di Dinas Pemberdayaan Masyarakat Dan Desa Kabupaten Labuhanbatu Selatan harus mampu menjadi leader bagi bawahannya sehingga pegawai selalu termotivasi dalam bekerja dengan memberikan pelayanan yang baik kepada masyarakat, memberikan masukkan ke atasan agar kemajuan Dinas Pemberdayaan Masyarakat Dan Desa Kabupaten Labuhanbatu Selatan dapat terealisasi dengan cepat. Fenomena tentang kepemimpinan di Dinas Pemberdayaan Masyarakat Dan Desa Kabupaten Labuhanbatu Selatan diantaranya atasan dalam memberikan tugas ke bawahan belum merata, dan masih kurangnya staf yang mendapat tanggungjawab terhadap pekerjaan yang penting.

Selain faktor motivasi intrinsik dan kepemimpinan, masih ada faktor lainnya yang dapat mempengaruhi kinerja pegawai Dinas Pemberdayaan Masyarakat Dan Desa Kabupaten Labuhanbatu Selatan yaitu disiplin kerja. Penelitian Ageng (2015:78) menyatakan bahwa disiplin berpengaruh positif terhadap kinerja pegawai Pada PT. PLN Cabang Weleri sebesar 44,15\%, dan penelitian Aldrianto (2016:114) menyatakan bahwa disiplin berpengaruh terhadap kinerja pegawai pada PT. Kospermindo di Makasar sebesar 47,22\%. Kedua penelitiaan ini menghasilkan pengaruh yang sedang sehingga layak untuk dilakukan penelitian lanjutan. Teori Handoko (2015:112), menyatakan bahwa disiplin adalah suatu ketaatan yang sungguh-sungguh yang didukung oleh kesadaran untuk menjalankan tugas dan kewajibannya serta berperilaku yang seharusnya berlaku di dalam lingkungan tertentu. Sedangkan pengertian kerja adalah perbuatan melakukan sesuatu kegiatan yang bertujuan mendapatkan hasil. Berdasarkan pendapat di atas, maka dapat dikatakan bahwa disiplin adalah sikap dari individu atau kelompok yang mencerminkan ketaatan dan kepatuhan terhadap peraturan yang berlaku di dalam suatu organisasi. Sedangkan pengertian disiplin kerja dapat dikatakan sebagai sikap dari seseorang atau kelompok yang taat dan patuh terhadap peraturan atau tata tertib yang berlaku, dalam melakukan tugas dan kewajibannya pada suatu organisasi untuk mencapai tujuan. Ada dua tipe disiplin yaitu preventif dan korektif. Disiplin preventif adalah kegiatan yang dilaksanakan untuk mendorong para pegawai agar mengikuti berbagai standar dan aturan, sehingga penyelewengan-penyelewengan dapat dicegah. Disiplin korektif adalah kegiatan yang diambil untuk menangani pelanggaran terhadap aturan-aturan dan mencoba untuk menghindari pelanggaran-pelanggaran lebih lanjut. Fenomena tentang disiplin kerja pegawai Dinas Pemberdayaan Masyarakat Dan Desa Kabupaten Labuhanbatu Selatan antara lain masih ada pegawai yang tidak masuk kerja tanpa alasan yang jelas dan masih ada pegawai yang tidak berada di tempat kerja pada waktu jam dinas.

\subsection{Batasan Masalah}

Mengingat ada beberapa permasalahan yang teridentifikasi dan dikarenakan waktu serta kemampuan yang penulis miliki dalam melaksanakan penelitian ini masih kurang, maka dari masalah-masalah yang teridentifikasi tersebut penulis mencoba membatasi masalah yang akan diteliti hanya pada masalah motivasi intrinsik, kepemimpinan, disiplin kerja dan kinerja pegawai.

\subsection{Hioptesis}

Hipotesis adalah jawaban sementara terhadap masalah penelitian, yang kebenarannya harus diuji secara empiris. Hipotesis dalam penelitian ini adalah :

1) Motivasi interinsik berpengaruh positif dan signifikan terhadap kinerja pegawai Dinas Pemberdayaan Masyarakat Dan Desa Kabupaten Labuhanbatu Selatan.

2) Kepemimpinan berpengaruh positif dan signifikan terhadap kinerja pegawai Dinas Pemberdayaan Masyarakat Dan Desa Kabupaten Labuhanbatu Selatan.

3) Disiplin kerja berpengaruh positif dan signifikan terhadap kinerja pegawai Dinas Pemberdayaan Masyarakat Dan Desa Kabupaten Labuhanbatu Selatan.

4) Motivasi interinsik, kepemimpinan dan disiplin kerja berpengaruh positif dan signifikan terhadap kinerja pegawai Dinas Pemberdayaan Masyarakat Dan Desa Kabupaten Labuhanbatu Selatan. 


\subsection{Tujuan Penelitian}

Tujuan penelitian ini adalah :

1) Untuk mengetahui dan menganalisis pengaruh motivasi intrinsik terhadap kinerja pegawai Dinas Pemberdayaan Masyarakat Dan Desa Kabupaten Labuhanbatu Selatan.

2) Untuk mengetahui dan menganalisis pengaruh kepemimpinan terhadap kinerja pegawai Dinas Pemberdayaan Masyarakat Dan Desa Kabupaten Labuhanbatu Selatan.

3) Untuk mengetahui dan menganalisis pengaruh disiplin kerja terhadap kinerja pegawai Dinas Pemberdayaan Masyarakat Dan Desa Kabupaten Labuhanbatu Selatan.

4) Untuk mengetahui dan menganalisis pengaruh motivasi intrinsik, kepemimpinan dan disiplin kerja terhadap kinerja pegawai Dinas Pemberdayaan Masyarakat Dan Desa Kabupaten Labuhanbatu Selatan.

\section{Metode Penelitian}

\subsection{Populasi}

Menurut Sugiyono (2011: 55), populasi adalah wilayah generalisasi yang terdiri atas obyek/subjek yang mempunyai kuantitas dan karakteristik tertentu yang ditetapkan oleh peneliti untuk dipelajari dan kemudian ditarik kesimpulannya. Jadi populasi bukan hanya orang tetapi juga benda-benda alam yang lain. Populasi juga bukan sekedar jumlah yang ada pada objek/subjek yang dipelajari, tetapi meliputi seluruh karakteristik, sifat yang dimiliki objek/subjek itu. Dari pengertian tersebut, maka dapat disimpulkan bahwa populasi merupakan subjek penelitian dimana individu yang akan dikenai perilaku atau dapat dikatakan sebagai keseluruhan objek penelitian yang akan diteliti. Maka yang menjadi populasi dalam penelitian ini adalah pegawai Dinas Pemberdayaan Masyarakat Dan Desa Kabupaten Labuhanbatu Selatan yang berjumlah 36 orang.

Tabel 1. Kerangka populasi pegawai

\begin{tabular}{|c|l|c|}
\hline No & \multicolumn{1}{|c|}{ Keterangan } & $\begin{array}{c}\text { Jumlah } \\
\text { (Orang) }\end{array}$ \\
\hline 1 & Sekretariat & 6 \\
\hline 2 & $\begin{array}{l}\text { Bidang Pemberdayaan dan } \\
\text { Partisipasi Masyarakat }\end{array}$ & 8 \\
\hline 3 & $\begin{array}{l}\text { Bidang Usaha Masyarakat dan } \\
\text { Sumber Daya Alam }\end{array}$ & 7 \\
\hline 4 & $\begin{array}{l}\text { Bidang Pemberdayaan } \\
\text { Teknologi Tepat Guna }\end{array}$ & 8 \\
\hline 5 & $\begin{array}{l}\text { Bidang Pemerintahan } \\
\text { Desa/Kelurahan }\end{array}$ & 7 \\
\hline \multicolumn{1}{|c|}{ Jumlah } & 36 \\
\hline
\end{tabular}

Sumber: Dinas Pemberdayaan Masyarakat Dan Desa Kabupaten

Labuhanbatu Selatan, 2020

\subsection{Sampel}

Menurut Arikunto (2011: 78), teknik sampling merupakan teknik pengambilan sampel, sedangkan sampel adalah sebagian dari jumlah dan karanteristik yang dimiliki oleh populasi. Dengan teknik penarikan sampel secara total sampling, maka sampel dalam penelitian ini seluruh populasi yaitu 36 orang pegawai Dinas Pemberdayaan Masyarakat Dan Desa Kabupaten Labuhanbatu Selatan.

\subsection{Uji Normalitas}

Uji normalitas adalah untuk melihat apakah nilai residual terdistribusi normal atau tidak. Model regresi yang baik adalah memiliki nilai residual yang terdistribusi normal. Jadi uji normalitas bukan dilakukan pada masingmasing variabel tetapi pada nilai residualnya. Sering terjadi kesalahan yang jamak yaitu bahwa uji normalitas dilakukan pada masingmasing variabel. Hal ini tidak dilarang tetapi model regresi memerlukan normalitas pada nilai residualnya bukan pada masing-masing variabel penelitian.

Pengujian normalitas data penelitian adalah untuk menguji apakah dalam model statistik variabel-variabel penelitian berdistribusi normal atau tidak normal. Model regresi yang tinggi adalah memiliki distribusi normal atau mendekati normal. Untuk menguji apakah distribusi data normal atau tidak, salah satunya dengan menggunakan metode gambar normal Probabilitas Plots digunakan untuk menyimpulkan apakah model analisis memenuhi asumsi normal, dengan penyebaran data di sekitar garis diagonal dan mengikuti arah garis diagonal maka data tersebut mememenuhi asumsi normal dalam model analisis, yang dapat dilihat pada gambar dibawah ini :

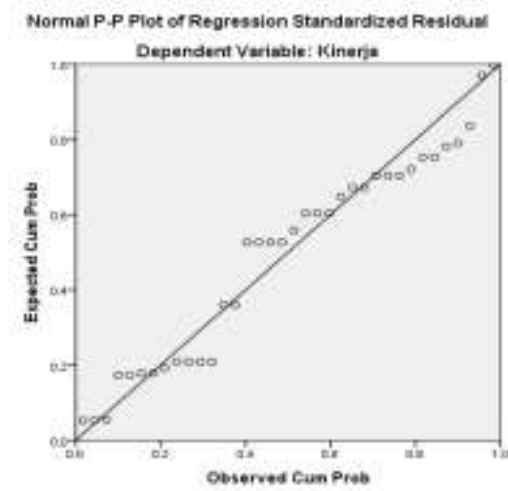

Gambar 1. Uji asumsi normalitas pengaruh motivasi intrinsik, kepemimpinan dan disiplin kerja terhadap kinerja 
Tabel 2. One-Sample Kolmogorov-Smirnov Test

\begin{tabular}{|ll|r|}
\hline & & \multicolumn{1}{|c|}{ Kinerja } \\
\hline $\mathrm{N}$ & & 36 \\
Normal Parameters $^{\mathrm{a}, \mathrm{b}}$ & Mean & 43.8333 \\
& Std. Deviation & 3.06594 \\
Most Extreme & Absolute & .149 \\
Differences & Positive & .144 \\
& Negative & -.149 \\
Kolmogorov-Smirnov Z & & .894 \\
Asymp. Sig. (2-tailed) & & .401 \\
\hline a. Test distribution is Normal. & \\
b. Calculated from data. &
\end{tabular}

Berdasarkan Tabel 2, diatas diketahui signifikansi sebesar 0.206. Nilai signifikansi ini lebih besar dari 0.05, sehingga dapat disimpulkan bahwa data yang diuji berdistribusi normal.

\subsection{Uji Asumsi Multikolinieritas}

Multikolinieritas berati adanya hubungan yang kuat diantara beberapa atau semua variabel bebas pada model regresi. Jika terdapat multikolinieritas maka koefisien regresi menjadi tidak tentu, tingkat kesalahannya menjadi sangat besar dan biasanya ditandai dengan koefisien determinasi yang sangat besar tetapi pada pengujian parsial koefisien regresi, tidak ada atau pun kalau ada sangat sedikit sekali koefisien regresi yang signifikan. Pada penelitian ini digunakan nilai Variance Inflantion Factorrs (VIF) sebagai indikator ada tidaknya multikolinearitas di antara variabel bebas.
Tabel 3. Uji asumsi multikolinieritas pengaruh motivasi intrinsik, kepemimpinan dan disiplin kerja terhadap kinerja

\begin{tabular}{|l|c|c|}
\hline \multirow{2}{*}{ Variabel } & \multicolumn{2}{c|}{ Collinearity Statistics } \\
\cline { 2 - 3 } & Tolerance & VIF \\
\hline Motivasi intrinsik & 0.671 & 1.489 \\
\hline Kepemimpinan & 0.800 & 1.249 \\
\hline Disiplin kerja & 0.630 & 1.587 \\
\hline
\end{tabular}

a Dependent Variable : Kinerja

Berdasarkan nilai VIF yang diperoleh seperti terlihat pada tabel 3 diatas sebesar $1.489,1.249,1.587$, dimana nilai VIF dari ketiga varibel bebas lebih kecil dari 10 dan dapat disimpulkan tidak terdapat multikolinieritas diantara ketiga variabel bebas dalam penelitian ini.

\subsection{Uji Asumsi Autokorelasi}

Autokorelasi sebagai suatu korelasi antara nilai variabel dengan nilai variabel yang sama pada lag satu atau lebih sebelum nya. Menurut Cornelius (2015: 212), kisaran nilai uji autokorelasi yang dilakukan dalam pengujian Durbin Watson (DW) sebagai berikut :

$1.65<\mathrm{DW}<2.35$ tidak terjadi autokorelasi 1.21. $<\mathrm{DW}<1.65$ atau $2.35<\mathrm{DW}<2.79$ tidak dapat disimpulkan.

$\mathrm{DW}<1.21$ atau DW $>2.79$ terjadi autokorelasi.

Tabel 4. Model summary ${ }^{\mathrm{b}}$ pengaruh motivasi intrinsik, kepemimpinan dan disiplin kerja terhadap kinerja

\begin{tabular}{|l|r|r|r|r|r|r|}
\hline \multirow{4}{*}{ Model } & \multicolumn{5}{|c|}{ Change Statistics } & \multirow{2}{*}{$\begin{array}{c}\text { Durbin- } \\
\text { Watson }\end{array}$} \\
\cline { 2 - 6 } & $\begin{array}{c}\text { R Square } \\
\text { Change }\end{array}$ & F Change & df1 & df2 & $\begin{array}{c}\text { Sig. F } \\
\text { Change }\end{array}$ & \\
\hline 1 & .734 & 29.430 & 3 & 32 & .000 & 1.931 \\
\hline
\end{tabular}


Berdasarkan Tabel 4 di atas diperoleh nilai statistik Durbin-Watson (DW) diperoleh nilai 1.931, nilai tersebut berada pada kisaran $1.65<\mathrm{DW}<2.35$ maka dapat disimpulkan tidak terdapat autokorelasi pada model regresi. Setelah ketiga asumsi regresi diuji, selanjutnya dilakukan pengujian hipotesis.

\section{Evaluasi Data dan Uji Hipotesis.}

Dalam evaluasi data ini peneliti akan menguji kebenaran hipotesis baik itu secara simultan atau bersama-sama, maupun secara partial atau sendiri-sendiri dan untuk

Tabel 5. Coefficients ${ }^{\mathrm{a}}$ pengaruh motivasi intrinsik, kepemimpinan dan disiplin kerja terhadap kinerja

\begin{tabular}{|c|c|c|c|c|c|c|}
\hline \multirow{2}{*}{\multicolumn{2}{|c|}{ Model }} & \multicolumn{2}{|c|}{$\begin{array}{l}\text { Unstandardized } \\
\text { Coefficients }\end{array}$} & \multirow{3}{*}{$\begin{array}{c}\text { Standardized } \\
\text { Coefficients } \\
\text { Beta }\end{array}$} & \multirow{2}{*}{$\mathrm{t}$} & \multirow{2}{*}{ Sig. } \\
\hline & & $\mathrm{B}$ & Std. Error & & & \\
\hline 1 & (Constant) & 3.852 & 4.358 & & .884 & .383 \\
\hline & Motivasi intrinsik & .336 & .111 & .337 & 3.028 & .005 \\
\hline & Kepemimpinan & .161 & .071 & .230 & 2.256 & .031 \\
\hline & Disiplin kerja & .414 & .098 & .485 & 4.225 & .000 \\
\hline
\end{tabular}

a Dependent Variable: Kinerja

Berdasarkan Tabel 5, out put SPSS "Coefficients" diatas, persamaan regresi linier berganda adalah sebagai berikut :

$$
\begin{aligned}
& Y=3.852+0.336 X_{1}+0.161 X_{2}+ \\
& 0.414 X_{3}+e
\end{aligned}
$$

Berdasarkan persamaan regresi linier berganda ini, maka dapat dijelaskan maksud dari persamaan di atas :

1) Nilai konstanta dari persamaan regresi dari penelitian ini sebesar 3.852, hal ini menyatakan bahwa nilai variabel kinerja pegawai Dinas Pemberdayaan Masyarakat Dan Desa Kabupaten Labuhanbatu Selatan sebesar 3.852.

2) Koefisien regresi untuk variabel motivasi intrinsik sebesar 0.336, hal ini menjelaskan bahwa variabel motivasi intrinsik berpengaruh positif terhadap kinerja pegawai Dinas Pemberdayaan Masyarakat Dan Desa Kabupaten Labuhanbatu Selatan

3) Koefisien regresi untuk variabel kepemimpinan sebesar 0.161, hal ini menjelaskan bahwa variabel kepemimpinan memudahkan peneliti dalam pengolahan data, maka digunakan Program SPSS versi 23.00.

\subsection{Analisis Regresi Linier Berganda}

Analisis regresi linier berganda ini digunakan untuk mengestimasi pengaruh motivasi intrinsik, kepemimpinan dan disiplin kerja terhadap kinerja pegawai Dinas Pemberdayaan Masyarakat Dan Desa Kabupaten Labuhanbatu Selatan. Berdasarkan hasil pengolahan data diperoleh hasil sebagai berikut : 
Dari Tabel 6 diatas diperoleh nilai $\mathrm{t}_{\text {hitung }}$ sebesar 3.369. Penelitian ini menggunakan taraf signifikansi $(\alpha ; 0,05)$ dan Derajat Kebebasan (DK) dengan ketentuan DK $=\mathrm{n}-2$, atau 36-2 $=34$. Dengan ketentuan tersebut, diperoleh nilai $t_{\text {tabel }}$ sebesar 2.018. Dengan kriteria hipotesis sebagai berikut :

Jika $\mathrm{t}_{\text {hitung }}>\mathrm{t}_{\text {tabel }}$, maka $\mathrm{H}_{0}$ ditolak dan $\mathrm{Ha}$ diterima.

Jika $\mathrm{t}_{\text {hitung }}<\mathrm{t}_{\text {tabel }}$, maka $\mathrm{H}_{0}$ diterima dan $\mathrm{Ha}$ ditolak.

Berdasarkan hasil pengolahan data penelitian, diperoleh nilai $t_{\text {hitung }}>t_{\text {tabel }}(3.028>$ 2.018) dan nilai signifikasi $0.005<0.05$, sehingga $\mathrm{H}_{0}$ ditolak dan $\mathrm{Ha}$ diterima. Artinya variabel motivasi intrinsik berpengaruh positif dan signifikan terhadap kinerja pegawai Dinas Pemberdayaan Masyarakat Dan Desa Kabupaten Labuhanbatu Selatan. Besarnya pengaruh variabel motivasi intrinsik terhadap kinerja pegawai Dinas Pemberdayaan Masyarakat Dan Desa Kabupaten Labuhanbatu Selatan sebesar 0.337 atau $33.70 \%$. Hasil penelitian ini sejalan dengan hasil penelitian terdahulu dari Ruqo'iye (2012), Saeed et.al (2016), Ali et.al (2016), dan Nurchayani et.al
(2016). Pegawai yang mau dan rela mengerahkan kemampuan dalam bentuk keahlian atau keterampilan, tenaga dan waktunya untuk menyelenggarakan berbagai kegiatan yang menjadi tanggung jawabnya dalam rangka pencapaian tujuan dinas. Pegawai yang memiliki motivasi yang rendah mereka cenderung untuk memperlihatkan upaya yang tidak maksimal dalam melaksanakan pekerjaannya, sehingga semakin tinggi motivasi yang dimiliki oleh individu sebagai pegawai maka dapat meningkatkan kinerja pegawai itu sendiri.

\subsection{Pengaruh Kepemimpinan Terhadap Kinerja Pegawai Dinas Pemberdayaan Masyarakat Dan Desa Kabupaten Labuhanbatu Selatan. \\ Untuk mengetahui pengaruh} kepemimpinan terhadap kinerja pegawai Dinas Pemberdayaan Masyarakat Dan Desa Kabupaten Labuhanbatu Selatan digunakan ujit, sedangkan untuk melihat besarnya pengaruh variabel bebas terhadap variabel terikat digunakan angka Beta atau Standardized Coefficient Beta.

Tabel. 7. Coeficients ${ }^{\mathrm{a}}$ pengaruh kepemimpinan terhadap kinerja

\begin{tabular}{|c|c|c|c|c|c|c|}
\hline \multirow{2}{*}{\multicolumn{2}{|c|}{ Model }} & \multicolumn{2}{|c|}{$\begin{array}{l}\text { Unstandardized } \\
\text { Coefficients }\end{array}$} & \multirow{2}{*}{$\begin{array}{c}\text { Standardized } \\
\text { Coefficients } \\
\text { Beta }\end{array}$} & \multirow{2}{*}{$\mathrm{t}$} & \multirow{2}{*}{ Sig. } \\
\hline & & B & Std. Error & & & \\
\hline 1 & (Constant) & 3.852 & 4.358 & & .884 & .383 \\
\hline & Kepemimpinan & .161 & .071 & .230 & 2.256 & .031 \\
\hline
\end{tabular}

Dari Tabel 7 diatas diperoleh nilai $t_{\text {hitung }}$ sebesar 2.256. Penelitian ini menggunakan taraf signifikansi $(\alpha ; 0,05)$ dan Derajat Kebebasan (DK) dengan ketentuan DK $=\mathrm{n}-2$, atau $36-2$ $=34$. Dengan ketentuan tersebut, diperoleh nilai $\mathrm{t}_{\text {tabel }}$ sebesar 2.018. Dengan kriteria hipotesis sebagai berikut :

Jika $\mathrm{t}_{\text {hitung }}>\mathrm{t}_{\text {tabel }}$, maka $\mathrm{H}_{0}$ ditolak dan $\mathrm{Ha}$ diterima.

Jika $\mathrm{t}_{\text {hitung }}<\mathrm{t}_{\text {tabel }}$, maka $\mathrm{H}_{0}$ diterima dan $\mathrm{Ha}$ ditolak.

Berdasarkan hasil pengolahan data penelitian, diperoleh nilai $t_{\text {hitung }}>t_{\text {tabel }}(2.256>$ 2.018) dan nilai signifikasi $0.031<0.05$, sehingga $\mathrm{H}_{0}$ ditolak dan $\mathrm{Ha}$ diterima. Artinya variabel kepemimpinan berpengaruh positif dan signifikan terhadap kinerja pegawai Dinas Pemberdayaan Masyarakat Dan Desa Kabupaten Labuhanbatu Selatan. Besarnya pengaruh variabel kepemimpinan terhadap kinerja pegawai Dinas Pemberdayaan Masyarakat Dan Desa Kabupaten Labuhanbatu Selatan sebesar 0.230 atau 23\%. Hasil penelitian ini sejalan dengan hasil penelitian dari Krisdiana (2014) dan Dwi Wahyu (2012) yang menyatakan kepemimpinan berpengaruh positif dan signifikan terhadap kinerja. Untuk mencapai tujuan bersama, pegawai di dinas perlu membina kebersamaan dengan mengikuti pengendalian dari pemimpinnya. Dengan pengendalian tersebut, perbedaan keinginan, kehendak, kemauan, perasaan, kebutuhan dan lain-lain dipertemukan untuk digerakkan kearah yang sama. Dengan demikian berarti di dalam setiap perbedaan individual pegawai dimanfaatkan untuk mencapai tujuan yang sama sebagai kegiatan kepemimpinan 
3.4. Pengaruh Disiplin Kerja Terhadap

Kinerja Pegawai Dinas Pemberdayaan

Masyarakat Dan Desa Kabupaten

Labuhanbatu Selatan.

Untuk mengetahui pengaruh disiplin kerja terhadap kinerja pegawai Dinas Pemberdayaan
Masyarakat Dan Desa Kabupaten Labuhanbatu Selatan digunakan uji-t, sedangkan untuk melihat besarnya pengaruh variabel bebas terhadap variabel terikat digunakan angka Beta atau Standardized Coefficient Beta.

Tabel. 8. Coeficients ${ }^{\mathrm{a}}$ pengaruh disiplin kerja terhadap kinerja

\begin{tabular}{|c|c|c|c|c|c|c|}
\hline \multirow{2}{*}{\multicolumn{2}{|c|}{ Model }} & \multicolumn{2}{|c|}{$\begin{array}{l}\text { Unstandardized } \\
\text { Coefficients }\end{array}$} & \multirow{3}{*}{$\begin{array}{c}\text { Standardized } \\
\text { Coefficients } \\
\text { Beta }\end{array}$} & \multirow{2}{*}{$\mathrm{t}$} & \multirow{2}{*}{ Sig. } \\
\hline & & B & Std. Error & & & \\
\hline 1 & (Constant) & 3.852 & 4.358 & & .884 & .383 \\
\hline & Disiplin kerja & .414 & .098 & .485 & 4.225 & .000 \\
\hline
\end{tabular}

Dari Tabel 8, diatas diperoleh nilai $\mathrm{t}_{\text {hitung }}$ sebesar 4.225. Penelitian ini menggunakan taraf signifikansi $(\alpha ; 0,05)$ dan Derajat Kebebasan (DK) dengan ketentuan DK $=\mathrm{n}-2$, atau $36-2$ $=34$. Dengan ketentuan tersebut, diperoleh nilai $t_{\text {tabel }}$ sebesar 2.018. Dengan kriteria hipotesis sebagai berikut :

Jika $\mathrm{t}_{\text {hitung }}>\mathrm{t}_{\text {tabel }}$, maka $\mathrm{H}_{0}$ ditolak dan $\mathrm{Ha}$ diterima.

Jika $\mathrm{t}_{\text {hitung }}<\mathrm{t}_{\text {tabel }}$, maka $\mathrm{H}_{0}$ diterima dan $\mathrm{Ha}$ ditolak.

Berdasarkan hasil pengolahan data penelitian, diperoleh nilai $t_{\text {hitung }}>t_{\text {tabel }}(4.225>$ 2.018) dan nilai signifikasi $0.000<0.05$, sehingga $\mathrm{H}_{0}$ ditolak dan $\mathrm{Ha}$ diterima. Artinya variabel disiplin kerja berpengaruh positif dan signifikan terhadap kinerja pegawai Dinas Pemberdayaan Masyarakat Dan Desa Kabupaten Labuhanbatu Selatan. Besarnya pengaruh variabel komitmen profesi terhadap kinerja pegawai Dinas Pemberdayaan Masyarakat Dan Desa Kabupaten Labuhanbatu Selatan sebesar 0.485 atau $48.50 \%$. Hasil penelitian ini sejalan dengan hasil penelitian terdahulu dari Ageng (2015:78) dan penelitian dari Aldrianto (2016:114). Ketaatan dari pegawai yang sungguh-sungguh didukung oleh kesadaran untuk menjalankan tugas dan kewajibannya serta berperilaku yang seharusnya berlaku di dalam lingkungan dinas. Sementara sikap dari pegawai yang

Tabel 9. Anova ${ }^{\mathrm{b}}$ pengaruh motivasi intrinsik, kepemimpinan dan disiplin kerja terhadap kinerja

\begin{tabular}{|l|l|r|r|r|r|c|}
\hline \multirow{3}{*}{ Model } & & $\begin{array}{c}\text { Sum of } \\
\text { Squares }\end{array}$ & \multicolumn{1}{c|}{ df } & $\begin{array}{c}\text { Mean } \\
\text { Square }\end{array}$ & \multicolumn{1}{c|}{ F } & Sig. \\
\hline \multirow{4}{*}{1} & Regression & 241.479 & 3 & 80.493 & 29.430 & $.000^{\mathrm{a}}$ \\
\cline { 2 - 7 } & Residual & 87.521 & 32 & 2.735 & & \\
\cline { 2 - 7 } & Total & 329.000 & 35 & & & \\
\hline
\end{tabular}

Dependent Variable: Kinerja mencerminkan ketaatan dan kepatuhan terhadap peraturan yang berlaku di dinas menunjukkan disiplin yang diterapkan dapat berjalan dengan baik.

\subsection{Pengaruh Motivasi Intrinsik, Kepemimpinan dan Disiplin Kerja Terhadap Kinerja Pegawai Dinas Pemberdayaan Masyarakat Dan Desa Kabupaten Labuhanbatu Selatan \\ Untuk mengetahui pengaruh motivasi} intrinsik, kepemimpinan dan disiplin kerja terhadap kinerja pegawai Dinas Pemberdayaan Masyarakat Dan Desa Kabupaten Labuhanbatu Selatan digunakan uji-F, dengan ketentuan sebagai berkut :

a. Jika nilai $F_{\text {hitung }}>F_{\text {tabel }}$ dan nilai probabilitas (p) $<$ tingkat signifikansi 5\% $(\alpha=0,05)$ maka hipotesis penelitian $\left(\mathrm{H}_{1}\right)$ diterima dan $\mathrm{H}_{0}$ ditolak.

b. Jika nilai $\mathrm{F}_{\text {hitung }}<\mathrm{F}_{\text {tabel }}$ dan nilai probabilitas (p) > tingkat signifikansi $5 \%(\alpha=0,05)$ maka hipotesis penelitian $\left(\mathrm{H}_{1}\right)$ ditolak dan $\mathrm{H}_{0}$ diterima.

Penelitian ini menggunakan taraf signifikansi $(\alpha \quad 0,05)$ dan Derajat Kebebasan (DK) dengan ketentuan numerator : jumlah variabel -1 atau $4-1=3$, dan jumlah sampel dikurang 4 atau $36-4=32$. Dengan ketentuan tersebut, diperoleh nilai $\mathrm{F}_{\text {tabel }}$ sebesar 2,66. 
Berdasarkan Tabel 9, out put SPSS "Anova" diatas diketahui nilai $F_{\text {hitung }}>F_{\text {tabel }}$ $(29.430>2,66)$ dan nilai signifikasi $0,000<$ 0,05, sehingga $\mathrm{H}_{0}$ ditolak dan $\mathrm{H}_{1}$ diterima. Artinya variabel motivasi intrinsik, kepemimpinan dan disiplin kerja secara simultan atau bersama-sama berpengaruh positif dan signifikan terhadap kinerja pegawai Dinas Pemberdayaan Masyarakat Dan Desa Kabupaten Labuhanbatu Selatan.

\subsection{Uji Determinan}

Uji determinan adalah untuk melihat seberapa besar pengaruh variabel motivasi intrinsik, kepemimpinan dan disiplin kerja terhadap kinerja pegawai Dinas Pemberdayaan Masyarakat Dan Desa Kabupaten Labuhanbatu Selatan secara simultan, maka dapat dilihat dari hasil perhitungan dalam model summary, khususnya angka $\mathrm{R}_{\text {Square }}$ dibawah ini :

Tabel 10 Model summary ${ }^{\mathrm{b}}$ pengaruh motivasi intrinsik, kepemimpinan dan disiplin kerja terhadap kinerja

\begin{tabular}{|l|c|r|r|r|}
\hline Model & $\mathrm{R}$ & R Square & $\begin{array}{c}\text { Adjusted R } \\
\text { Square }\end{array}$ & Std. Error of the Estimate \\
\hline 1 & $.857^{\mathrm{a}}$ & .734 & .709 & 1.65379 \\
\hline \multicolumn{4}{|l|}{ Dependent Variable: Kinerja }
\end{tabular}

Berdasarkan Tabel 10, out put SPSS "Model summary" diatas, diperoleh nilai $\mathrm{R}_{\text {Square }}$ $\left(\mathrm{r}^{2}\right)$ adalah 0,734 . Nilai tersebut mempunyai maksud bahwa pengaruh variabel motivasi intrinsik, kepemimpinan dan disiplin kerja terhadap kinerja pegawai Dinas Pemberdayaan Masyarakat Dan Desa Kabupaten Labuhanbatu Selatan sebesar $73.40 \%$, sedangkan sisanya sebesar $26.60 \%(100 \%$ - $73.40 \%)$ dipengaruhi oleh faktor-faktor lain yang tidak diteliti. Dengan kata lain variabilitas kinerja pegawai Dinas Pemberdayaan Masyarakat Dan Desa Kabupaten Labuhanbatu Selatan dapat diterangkan oleh variabel motivasi intrinsik, kepemimpinan dan disiplin kerja sebesar $73.40 \%$, sedangkan sisanya sebesar $26.60 \%$ disebabkan oleh variabel-variabel lain diluar model penelitian ini.

\section{Kesimpulan}

Berdasarkan pada analisis dan evaluasi data pada bab sebelumnya, maka dapat ditarik kesimpulan sebagai berikut :

1) Variabel motivasi instrinsik berpengaruh positif dan signifikan terhadap kinerja pegawai Dinas Pemberdayaan Masyarakat Dan Desa Kabupaten Labuhanbatu Selatan.

2) Variabel kepemimpinan berpengaruh positif dan signifikan terhadap kinerja pegawai Dinas Pemberdayaan Masyarakat Dan Desa Kabupaten Labuhanbatu Selatan.

3) Variabel disiplin kerja berpengaruh positif dan signifikan terhadap kinerja pegawai Dinas Pemberdayaan Masyarakat Dan Desa Kabupaten Labuhanbatu Selatan.

4) Variabel motivasi intrinsik, kepemimpinan dan disiplin kerja berpengaruh positif dan signifikan terhadap kinerja pegawai Dinas Pemberdayaan Masyarakat Dan Desa Kabupaten Labuhanbatu Selatan.

5) Pengaruh variabel motivasi intrinsik, kepemimpinan dan disiplin kerja terhadap kinerja pegawai Dinas Pemberdayaan Masyarakat Dan Desa Kabupaten Labuhanbatu Selatan sebesar $73.40 \%$, sedangkan sisanya sebesar $26.60 \%$ dipengaruhi oleh faktor-faktor lain yang tidak diteliti

\section{DAFTRA PUSTAKA}

Ageng Prawatya (2015), Pengaruh Motivasi, Kemampuan dan disiplin kerja terhadap kinerja Pegawai Pada PT. PLN Cabang Weleri

Aldrianto Muhammad (2016), Pengaruh Disiplin dan Loyalitas Terhadap Kinerja Pegawai Pada PT. Kospermindo di Makasar Ali, A.Y.S., Dahie, A.M., dan Ali, A.A. (2016). Teacher Motivation and School Performance, the Mediating Effect of Job Satisfaction: Survey from Secondary Schools in Mogadishu. International Journal of Education and Sosial Science Vol. 3 No. 1. January 2016

Barnardin, H. John Joyce E.A. Ressul (2016), Human Resources, Mc Graw Hill, Inc, Singapore

Dovian Millian, Sudibjo Aji (2017), Pengaruh Kepemimpinan Dan Motivasi Terhadap Kinerja Karyawan Pada PT. Cat Di Kota Malang,

http://journal.umg.ac.id/index.php/manajeria 1/article/view/186 
Gibson, (2016), Manajemen Personalia, Ghalia Indonesia, Jakarta

Gorda, IGN. (2014), Manajemen Sumber Daya Manusia. Edisi Revisi. Cetakan Kedua. Denpasar: Astabrata

Handoko T, Hani (2015), Manajemen Personalia dan Sumber Daya Manusia, Edisi Kedua, BPFE Yogyakarta.

Hasibuan, Malayu, SP (2011), Manajemen Sumber Daya Manusia, PT. Bumi Akasara Jakarta.

Husnan, Keldjrachman Suad, (2016), Manajemen Personalia, Edisi ke Empat, BPFE Yogyakarta

Krisdiana dan Marimin (2014), Pengaruh Tingkat Pendidikan, Fasilitas Kerja dan Kepemimpinan Terhadap Kinerja Pegawai Kecamatan Se-Kota Tegal, Vol.3 No.2 Economic Education Analysis Journal

Mangkunegara, Anwar, Prabu. (2012). Evaluasi Kinerja SDM, Cetakan 4, Bandung : Refika Aditama

Martoyo, Susili (2016), Manajemen Sumber Daya Manusia, Edisi Ketiga, Cetakan Keempat, Ghalia Jakarta

Maskur, (2010), Analisis Budaya Organisasi, Motivasi Kerja Terhadap Fleksibilitas Organisasi dan Kinerja Pelayanan Pada Kantor Kecamatan Di Wilayah Kota Makassar. Tesis Ilmu Manajemen, Program Pascasarjana Universitas Brawijaya Malang

Mathis L. Robert dan Jackson H. John alih bahasa oleh Sadeli (2014), Manajemen Sumber Daya Manusia, Salemba Empat Jakarta.

Muchtar Adama (2014), Analisis Pengaruh Budaya Organisasi, Disiplin Kerja dan Semangat Kerja Terhadap Kinerja Pegawai Dinas Pendidikan Kabupaten Sragen

Murgianto, Sulasmi, S., dan Suhermin. (2016). Effects of Commitment, Competence, Work Satisfaction on Motivation and Performance of Employees at Integrated Service Office of east Java. International Journal of Advanced Research (2016), Volume 3, Issue -378-396

Nair, P.P dan Ganesh, S.S. (2016). Effects of Motivation, Stress and Compensation Benefits on Employee Performance in IT Progessionals. International Journal of Advanced Research (2016), Volume 4, Issue 1, 1349- 1357

Nitisemito S Alex (2011), Manajemen Personalia, Cetakan Keempat, Ghalia, Jakarta.
Nurchayani, N.M dan Adnyani, I.G.A.D. (2016). Pengaruh Kompensasi dan Motivasi terhadap Kinerja karyawan dengan kepuasan Kerja sebagai Variabel Intervening. E-Jurnal Manajemen Unud, Vol. 5, No.1, 2016

Raditya Singgih J (2016), Pengaruh Disiplin Kerja Dan Budaya Organisasi Terhadap Kinerja Pegawai CV. Abank Irenk Creative Yogyakarta

Rivai, Veithzal dan Sagala, Ella Jauvani. (2011). Manajemen Sumber Daya Manusia Untuk Perusahaan : Dari Teori ke Praktek. Jakarta : PT. Rajagrafindo Persada

Robbins P. Stephen, Coulter Mary alih bahasa oleh Benyamin, (2013), Manajemen, Edisi keenam, Jilid 2, PT. Indeks Jakarta

Ruqo'iye, Ruqo'iye (2012) Pengaruh motivasi intrinsik terhadap kinerja karyawan: Studi kasus pada PT. Bank Tabungan Negara (Persero) Tbk. kantor cabang syariah Malang. Undergraduate thesis, Universitas Islam Negeri Maulana Malik Ibrahim.

Saeed, S., dan Syah, F.M (2016). Impact of Performance Appraisal on Employee Motivation in Islamic Banking. Arabian Journal of Business and Management Review (OMAN Chapter). Vol. 5, No.7. February 2016

Siagian, Sondang. (2014). Manajemen Sumber Daya Manusia (cetakan 15). Jakarta: Bumi Aksara

Simamora, H. (2014). Manajemen Sumber Daya Manusia. Edisi Ketiga. Yogyakarta: Sekolah Tinggi Ilmu Ekonomi YKPN

Sinungan (2016), Filsafat Administrasi, Gunung Agung Jakarta

Sugiyono. (2011). Metode Penelitian Kuantitatif dan Kualitatif dan R \& D. Bandung : Alfabeta

Thoha, Miftah (2012), Kepemimpinan Dalam Manajemen, Rajawali Jakarta

Yuwalliatin, S. (2006). Pengaruh Budaya

Organisasi, Motivasi Dan Komitmen

Terhadap Kinerja Serta Pengaruhnya

Terhadap Keunggulan Kompetitif

Semarang. UNISULA. EKOBIS. Vol 7. No 2, 241-256

Wahjosumidjo (2014), Kepemimpinan dan Motivasi, Liberty Yogyakarta

Wibowo, (2010). Manajemen Kinerja. Cetakan Pertama. Jakarta: Raja Grafindo Persada. 